\title{
Inhalt
}

\section{DRITTES BUCH}

\section{Sachenrecht}

\section{Vierter Abschnitt}

Anh. $\$ 1011$ : Erbbaurechtsverordnung

S\$ $1-39$ ErbbauVO

Erbbaurecht - aufgeboben -

$\mathbb{S} 1012-1017$

\section{Fünfter Abschnitt}

Dienstbarkeiten ................................... \$\$ 1018-1093

Erster Titel. Grunddienstbarkeiten .........................\$ $\$ 1018-1029$

Zweiter Titel. Nießbrauch ............................ \$\$ 1030-1089

I. Nießbrauch an Sachen ............................. \$ \$1030-1067

II. Nießbrauch an Rechten .......................... \$\$ 1068-1084

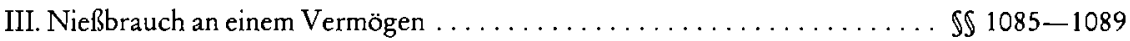

Dritter Titel. Beschränkte persönliche Dienstbarkeiten . . . . . . . . . . . . . . \$\$ 1090-1093

\section{Sechster Abschnitt}

Vorkaufsrecht

\section{Siebenter Abschnitt}

Reallasten

$\int \$ 1105-1112$

\section{Achter Abschnitt}

Hypothek. Grundschuld. Rentenschuld $\ldots \ldots \ldots \ldots \ldots \ldots \ldots \ldots \ldots \ldots \mathbb{\$} \$ 1113-1203$

Erster Titel. Hypothek ................................. \$\$ 1113-1190

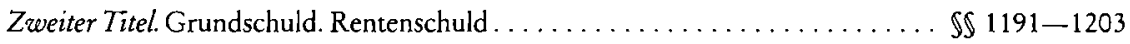

I. Grundschuld . . . . . . . . . . . . . . . . . . . . . . . . . \$ $\$ 1191-1198$

II. Rentenschuld . . . . . . . . . . . . . . . . . . . . . . . . . . \$ $\$ 1199-1203$

Anh. nach $₫ 1203$ (Schiffsrechtegesetz) $\ldots \ldots \ldots \ldots \ldots \ldots \ldots \ldots \ldots . \ldots \ldots$. $1-84$ SchiffsRG 
